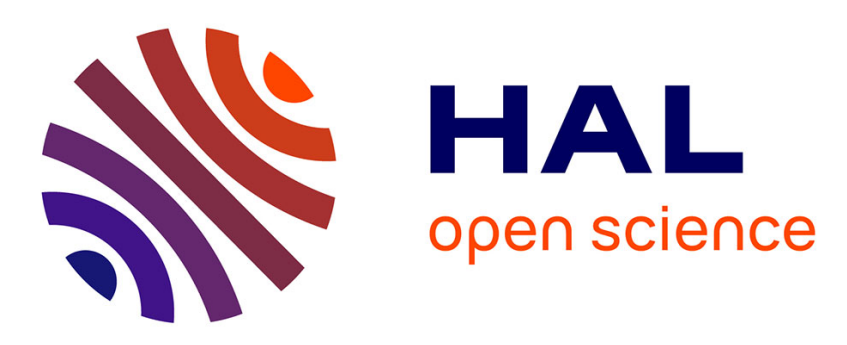

\title{
Very high resolution mapping of coral reef state using airborne bathymetric LiDAR surface-intensity and drone imagery
}

Antoine Collin, Camille Ramambason, Yves Pastol, Elisa Casella, Alessio Rovere, Lauric Thiault, Benoit Espiau, Gilles Siu, Franck Lerouvreur, Nao

Nakamura, et al.

\section{To cite this version:}

Antoine Collin, Camille Ramambason, Yves Pastol, Elisa Casella, Alessio Rovere, et al.. Very high resolution mapping of coral reef state using airborne bathymetric LiDAR surface-intensity and drone imagery. International Journal of Remote Sensing, In press, 10.1080/01431161.2018.1500072 . hal01848266

\section{HAL Id: hal-01848266 https://hal.science/hal-01848266}

Submitted on 24 Jul 2018

HAL is a multi-disciplinary open access archive for the deposit and dissemination of scientific research documents, whether they are published or not. The documents may come from teaching and research institutions in France or abroad, or from public or private research centers.
L'archive ouverte pluridisciplinaire HAL, est destinée au dépôt et à la diffusion de documents scientifiques de niveau recherche, publiés ou non, émanant des établissements d'enseignement et de recherche français ou étrangers, des laboratoires publics ou privés. 

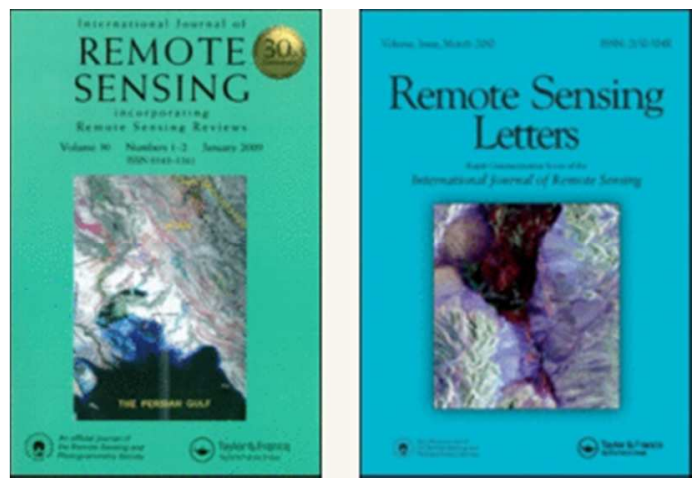

\section{Very high resolution mapping of coral reef state using airborne bathymetric LiDAR surface-intensity and drone imagery}

\begin{tabular}{|c|c|}
\hline Journal: & International Journal of Remote Sensing \\
\hline Manuscript ID & TRES-SIP-2017-0196.R5 \\
\hline Manuscript Type: & IJRS Special Issue Paper \\
\hline Date Submitted by the Author: & 22-Jun-2018 \\
\hline Complete List of Authors: & $\begin{array}{l}\text { Collin, Antoine; Ecole Pratique des Hautes Etudes (EPHE), PSL Research } \\
\text { University, CNRS UMR 6554 LETG; LABoratoire d'EXcellence CORAIL } \\
\text { Ramambason, Camille; Ecole Pratique des Hautes Etudes (EPHE), PSL } \\
\text { Research University, CNRS UMR 6554 LETG } \\
\text { Pastol, Yves; Service Hydrographique et Oceanographique de la Marine } \\
\text { Casella, Elisa; Leibniz-Zentrum fur Marine Tropenforschung GmbH, Leibniz } \\
\text { Center for Tropical Marine Ecology } \\
\text { Rovere, Alessio; Leibniz-Zentrum fur Marine Tropenforschung GmbH, } \\
\text { Leibniz Center for Tropical Marine Ecology; University of Bremen, MARUM } \\
\text { Thiault, Lauric; LABoratoire d'EXcellence CORAIL; PSL Research University, } \\
\text { EPHE-UPVD-CNRS } \\
\text { Espiau, Benoit; PSL Research University, EPHE-UPVD-CNRS } \\
\text { Siu, Gilles; PSL Research University, EPHE-UPVD-CNRS } \\
\text { Lerouvreur, Franck; PSL Research University, EPHE-UPVD-CNRS } \\
\text { Nakamura, Nao; LABoratoire d'EXcellence CORAIL; PSL Research } \\
\text { University, EPHE-UPVD-CNRS } \\
\text { Hench, James; Duke University, Nicholas School of the Environment } \\
\text { Schmitt, Russel; University of California Santa Barbara, Department of } \\
\text { Ecology, Evolution and Marine Biology, and Marine Science Institute } \\
\text { Holbrook, Sally; University of California Santa Barbara, Department of } \\
\text { Ecology, Evolution and Marine Biology, and Marine Science Institute } \\
\text { Troyer, Matthias; Eidgenossische Technische Hochschule Zurich fur } \\
\text { Theoretische Physik; Microsoft Research } \\
\text { Davies, Neil; Gump South Pacific Research Station, University of California; } \\
\text { University of California Berkeley Institute for Data Science }\end{array}$ \\
\hline Keywords: & coral reefs, LIDAR, neural networks \\
\hline
\end{tabular}


1

2

3

4

5

6

7

8

9

10

11

12

13

14

15

16

17

18

19

20

21

22

23

24

25

26

27

28

29

30

31

32

33

34

35

36

37

38

39

40

41

42

43

44

45

46

47

48

49

50

51

52

53

54

55

56

57

58

59

60
Keywords (user defined): $\quad$ coral reefs, bathymetric LiDAR, drone

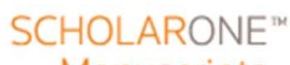

Manuscripts 
1 Very high resolution mapping of coral reef state using airborne 2 bathymetric LiDAR surface-intensity and drone imagery

3 Antoine Collin ${ }^{1,2 *}$, Camille Ramambason ${ }^{1}$, Yves Pastol ${ }^{3}$, Elisa Casella ${ }^{4}$, 4 Alessio Rovere ${ }^{4,5}$, Lauric Thiault ${ }^{2,6}$, Benoît Espiau ${ }^{6}$, Gilles Siu ${ }^{6}$, Franck 5 Lerouvreur $^{6}$, Nao Nakamura ${ }^{2,6}$, James L. Hench ${ }^{7}$, Russell J. Schmitt ${ }^{8}$, Sally 6 J. Holbrook $^{8}$, Matthias Troyer ${ }^{9,10}$, and Neil Davies ${ }^{11,12}$

$7 \quad{ }^{1}$ Ecole Pratique des Hautes Etudes (EPHE), PSL Research University, CNRS UMR

86554 LETG, Dinard, Brittany, France

$9 \quad{ }^{2}$ LABoratoire d'EXcellence CORAIL, Perpignan, France

$10{ }^{3}$ Service Hydrographique et Océanographique de la Marine, Brest, Brittany, France

$11{ }^{4}$ ZMT, Leibniz Center for Tropical Marine Ecology, Bremen, Germany

$12{ }^{5}$ MARUM, University of Bremen, Germany

$13{ }^{6}$ PSL Research University: EPHE-UPVD-CNRS, USR 3278 CRIOBE, Papetoai,

14 Moorea, French Polynesia

$15{ }^{7}$ Nicholas School of the Environment, Duke University, Beaufort, North Carolina,

16 United States

$17{ }^{8}$ Department of Ecology, Evolution and Marine Biology, and Marine Science Institute,

18 University of California Santa Barbara, Santa Barbara, California, United States

$19{ }^{9}$ Theoretische Physik, ETH Zurich, Zurich, Switzerland

$20{ }^{10}$ Microsoft Research, Redmond, Washington, USA

$21{ }^{11}$ Gump South Pacific Research Station, University of California, Moorea, French

22 Polynesia

$23{ }^{12}$ Berkeley Institute for Data Science, University of California, Berkeley, California, $24 U S A$

$25 \quad{ }^{*}$ Corresponding author: antoine.collin@ephe.sorbonne.fr, 0033299461072 


\section{Very high resolution mapping of coral reef state using airborne 2 bathymetric LiDAR surface-intensity and drone imagery}

Very high resolution (VHR) airborne data enable detection and physical measurements of individual coral reef colonies. The bathymetric LiDAR system, as an active remote sensing technique, accurately computes the coral reef ecosystem's surface and reflectance using a single green wavelength at the decimetre scale over 1-to-100 $\mathrm{km}^{2}$ areas. A passive multispectral camera mounted on an airborne drone can build a blue-green-red (BGR) orthorectified mosaic at the centimetre scale over 0.01 -to- $0.1 \mathrm{~km}^{2}$ areas. A combination of these technologies is used for the first time here to map coral reef ecological state at the submeter scale. Airborne drone BGR values $(0.03 \mathrm{~m}$ pixel size $)$ serve to calibrate airborne bathymetric LiDAR surface and intensity data $(0.5 \mathrm{~m}$ pixel size $)$. A classification of five ecological states is then mapped through an artificial neural network (ANN). The classification was developed over a small area $\left(0.01 \mathrm{~km}^{2}\right)$ in the lagoon of Moorea Island (French Polynesia) at VHR $(0.5 \mathrm{~m}$ pixel size) and then extended to the whole lagoon $\left(46.83 \mathrm{~km}^{2}\right)$. The ANN was first calibrated with 275 samples to determine the class of coral state through LiDAR-based predictors, then the classification was validated through 135 samples, reaching a satisfactory performance (overall accuracy $=0.75$ ).

Keywords: coral reefs, state, LiDAR, drone, neural network

\section{Introduction}

Coral reefs host $25 \%$ of the marine biodiversity but are increasingly subject to global ocean-climate changes and local anthropogenic activities (Bellwood 2004). Fine-scale monitoring of coral reef ecosystems and associated ecosystem services is needed for their management and spatial planning. Coral reef mapping usually relies on remote sensing for cost-effectively identifying their structural complexity, benthic composition, and regime surrogates over large areas (Goodman, Samuel and Stuart 2013; Hedley et al. 2016). Spaceborne multispectral imagery demonstrates great spatial potential to accurately map coral reef colonies (Collin, Hench, and Planes 2012), habitats (Collin et al. 2016), health (Collin and Planes 2012; Collin, Archambault, and Planes 2014) and resilience (Rowlands et al. 2012; Knudby et al. 2013; Collin, Nadaoka, and Bernardo 2015). Airborne passive hyperspectral imagery, provided with dozens of spectral bands, enables coral reef benthos, substrates and bathymetry to be significantly improved (Leiper et al. 2014). Airborne (usually on manned aircraft) active light detection and ranging (LiDAR) is now the reference system for measuring bathymetry, outperforming waterborne sound detection and ranging (SoNAR) devices, which are strongly impeded by shallow features, specifically in the coastal realm where coral reefs thrive (Costa, Battista, and Pittman 2009). LiDAR-derived morphometry indices can reveal efficient proxies for ecosystem characteristics, for example, estimates of reef fish assemblages (Wedding et al. 2008). Yet despite the increase in discrimination power showed over benthic habitats bathed with turbid waters, LiDAR indices have not been used to date to exploit the spectral information associated with water-penetrating green LiDAR wavelength for coral reef monitoring (Collin, Archambault, and Long 2008; Collin, Archambault, and Long 2011; Collin, Long, and Archambault 2011).

Unmanned airborne vehicles (UAVs, or simply 'drones') are becoming an integral component of the scientific toolbox for coral reef research and management. Equipped with blue-green-red (BGR) spectral cameras, drones are able to measure coral 
reef bathymetry and derived terrain roughness at very high resolution (VHR) using the photogrammetry approach (Leon et al. 2015; Casella et al. 2017). The 3D point cloud, permitting 2D orthorectified BGR mosaics and 2.5D digital surface models (DSM), results from the multi-angle information of a single scene made possible by spatiallyeven acquisition of BGR imagery from a moving airborne drone flying at low altitude (from 30 to $150 \mathrm{~m}$ ): so-called "structure-from-motion". The images and by-products yield spatial resolution at centimetre scale (i.e., $0.03 \mathrm{~m}$ pixel size). Coral reef states can be significantly distinguished using the resulting $0.03 \mathrm{~m}$ BGR orthomosaic drone dataset, enabling classification of reef ecological states.

Here we describe methodology for creating the first coral reef ecological state map at VHR based solely on regional airborne LiDAR "predictors" trained with local "response" imagery from drone. The bathymetric LiDAR Riegl VQ-820-G, mounted on a small plane or helicopter, serves as the remotely-sensed 1-to- $100 \mathrm{~km}^{2}$ predictors with four measurements of surface and intensity (green) per $\mathrm{m}^{2}$. The BGR GoPro, mounted on a consumer-grade airborne drone (DJI phantom 2), is used as the remotely-sensed 0.01-to- $0.1 \mathrm{~km}^{2}$ response. Spearheading machine learners in satellite-based coastal prediction (Collin, Etienne, and Feunteun 2017), an artificial neural network (ANN) classifier is developed to provide a robust, yet simple, algorithm linking the two datasets. Our study takes place on one of the best-studied islands in the world (Cressey 2015): Moorea (French Polynesia, Fig. 1), a volcanic island with fringing, barrier and outer coral reefs in the central South Pacific Ocean. It contributes to efforts to build a 4D model - an Island Digital Ecosystem Avatar (IDEA) - of Moorea and to simulate of future states of the social-ecological system in support of scenario-based planning (Davies et al. 2016). We follow a drone-based assessment of ecological state (coral reef state classification; Table 1) and combine it with LiDAR-based data to spatially classify the coral reef state at VHR over a small area and then extend this to the whole island. Findings are discussed with a view to how this approach could advance an automated workflow for coral reef mapping.

Figure 1

Table 1

\section{Materials and methods}

\subsection{Study site}

The study site is located in the northern lagoon of Moorea Island $\left(17^{\circ} 33^{\prime} \mathrm{S}, 149^{\circ} 50^{\prime} \mathrm{W}\right)$ in the Society Archipelago (French Polynesia, Fig. 1a). Moorea demonstrates a highly resilient coral reefs (Adjeroud et al. 2009), especially its outer slope, which following the extremely low coral cover (2\%) due to 2007-2010 outbreak of corallivore crown-ofthorne sea star (Acanthaster planci) and 2010 Oli cyclone strike, is recovering to record rates close to $70 \%$ (Chancerelle, pers. comm.). Located inside the $46.83 \mathrm{~km}^{2}$ Moorea lagoon, the study site covers $11710 \mathrm{~m}^{2}$ with maximum depth of $2 \mathrm{~m}$. It is bathed in oligotrophic, thus clear, seawater including various taxa of reef building corals (Porites, Acropora, Pocillopora, Montipora), red calcareous algae (Lithothamnium), fleshy algae (red, brown and green) and a diversity of geomorphic features (rubble, sand and pavement). 


8

19

.

2

23

4

5

6

0

(
study limits to the shallow waters $(<10 \mathrm{~m}$ depth), LiDAR intensity has been directly processed with no water correction. As each LiDAR surface and intensity sounding is duly located by the combination of HR global navigation satellite system and inertial measurement unit, digital surface and intensity models (DSM and DIM, Fig. 2b and 2c) can be calculated using ordinary kriging method applied to LiDAR sounding clouds. LiDAR points and rasters were geographically referenced to WGS84 UTM 6S and altimetrically zeroed as the mean sea level (SHOM 2016). Drone-derived imagery was registered with LiDAR data using a $1^{\text {st }}$ degree polynom function and resampled with cubic convolution.

\subsection{Artificial neural network classification}

Given their performance in a comparative analysis (Collin, Etienne, and Feunteun 2017), we use an ANN approach as a classification procedure binding the drone-based air-truth and LiDAR-based variables.

The ANN builds non-linear classifications by minimizing least squares using a multi-layer perceptron classifying ecological state response, $h(X)$, (Table 1) with the LiDAR surface and intensity predictors, $X$, through a constant, $k$, and intermediate 
1 weighted, $w_{i}$, functions called neurons, $n_{i}$ (Heermann and Khazenie 1992):

$$
h(X)=k\left(\sum_{i} w_{i} n_{i}(X)\right)
$$

Neurons $n_{i}$ are hereinafter based on hyperbolic tangents. ANN constrained by a single hidden layer provided with two neurons so the number of neurons to be in synergy with the number of inputs (predictors, Fig. 3). Trained by the 275 calibration samples, the ANN will be validated by the remaining 135 validation samples.

Figure 3

\subsection{Performance analysis \\ The agreement between validation and classified pixels in the five ecological states was quantified using the confusion matrix, from which overall, producer's and user's accuracies (OA, PA and UA, respectively) were computed (Congalton and Green 2009). PA and UA were calculated as the correctly classified pixels in each coral state divided by the number of calibration pixels of the corresponding state, and the total number of pixels that were classified in that state, respectively. OA was reckoned as the correctly classified pixels in all states divided by the total number of pixels.}

\section{Results}

\subsection{Local coral reef state at very high resolution}

The OA of the ANN classification reached a satisfactory performance $(O A=0.75)$, showing that the dual combination of LiDAR surface and intensity variables had a robust explanatory power of the variability of coral reef states (Table 2). Contrary to coral reef states 1,5 and 3 that were adequately assigned (UA=0.84, 0.80 and 0.74 , respectively), intermediate coral reef states 2 and 4 were moderately classified with UA of 0.68 and 0.68 , respectively (Table 2). Contrary to UA statistics, PA measures were evenly correct (From 0.81 to 0.71 , Table 2 ). The ANN classifier was applied to each pixel of LiDAR DSM and DIM (Fig $2 b$ and $2 c$, respectively) in order to continuously map ecological state (Fig. $4 b)$ provided with $0.5 \mathrm{~m}$ spatial resolution $(142 \times 422$ pixels).

Table 2

Figure 4

\subsection{Moorea coral reef state at very high resolution}

Insofar as the ANN prediction was adequate enough to be extended, the digital ecological classification was mapped at the island scale. Moorea LiDAR DSM and DIM were first rasterized at $0.5 \mathrm{~m}$ spatial resolution (Fig. $5 a$ and $5 b$ ) and then entered as inputs to the ANN classification, which produced a digital model of coral reef ecological state over the whole island (Fig. $5 c, 40364 \times 34588$ pixels). Moorea classes are dominated by sand on pavement $(56.8 \%)$, followed by Porites stony corals $(14.1 \%)$ and Microalgae on rubble (13.8\%), then Acropora/Pocillopora/Montipora stony corals with red calcareous algae (10.9\%), and finally Acropora/Pocillopora/Montipora stony corals (4.4\%). Overall, the coverage of hard corals (from state 1 to 3 ) appears significantly greater in the leeward side than the windward side.

Figure 5 


\section{Discussion}

\subsection{Airborne drone as "air-truth"}

The five coral reef ecological states were based on VHR BGR orthorectified mosaic derived from a consumer-grade multispectral camera driven by an airborne drone. This innovative procedure is supported by our knowledge of in situ coral reef features that can be discriminated at the centimetre scale. Insofar as both ecological composition and structural complexity are easily deduced from the BGR dataset, relatively inexpensive drone deployment can be used to obtain air-truth data directly even in places with little technical capacity. The geolocated photographs can be remotely processed and analysed in the cloud, given a suitable internet connection. With an easy-to-implement flight planning mobile application, rapid surveys could be conducted at even very remote locations with little infrastructure/capacity after short-terms events such as cyclone/storm and bleaching. The number of states could be increased by either flying at lower altitude (to gain in spatial resolution) or using drone-mounted LiDAR that can enhance the vertical accuracy, for example, to differentiate coral from macroalgae (Leiper et al. 2014).

The use of this air-truth, in the form of a cost-efficient UAV-borne BGR orthomosaic, has a strong potential to be applicable to other worldwide coral lagoons and even to a large panel of coastal and aquatic areas, provided with relatively clear waters. This air-truth leverages a high ratio of covered space unit per time unit while collecting centimetre-scale data, considerably outperforming submerged acquisitions, hindered by the very high viscosity of water.

\subsection{Airborne LiDAR surface and intensity}

The gradient of ecological states (from 1, well-developed hard coral, to 5, sand) was positively correlated with both surface $(r=0.93)$ and intensity $(r=0.93)$, showing that coral coverage decreases with depth and LiDAR green reflectance. The coral shrinkage with depth can be explained by the coral growth and structural complexification towards the surface (as a photosynthetic symbiont), what corroborates results derived from a spaceborne reef health proxy (Collin, Hench, and Planes 2012). The negative trend between coral state and green reflectance coincides with in situ spectral measurements, making explicit a greater reflectance of increasingly depigmented blueand brown-mode coral reefs in the coral health chart (Leiper et al. 2009). This increase in green reflectance (decrease in green absorbance) is linked to the loss of peridinin pigments contained in symbiotic zooxanthellae living in coral tissues (Collin and Planes 2012). Even if most bathymetric LiDAR systems use the single green wavelength, this electromagnetic radiation is relevant to distinguish coral reef state as highlighted in the elaboration of both the green-purple and the "red edge"-green normalized difference ratios (Collin, Hench, and Planes 2012; Collin, Archambault, Planes 2014, respectively).

Inner classification results (UA) revealed that coral- and sand-dominant states (1, 3 and 5) were successfully recognized, contrary to both assemblages of corals and rubble colonized by calcareous and micro-algae ( 2 and 4$)$, respectively. We could assume that the spectral mixing due to the presence of algae on relatively "pure" states was not very effectively resolved by the ANN classifier built from only LiDAR surface and intensity. We advocate the experiment of a coral reef state classification using an innovative bathymetric LiDAR, augmented by an added spectral wavelength (i.e. 355 
$\mathrm{nm}$, as the third harmonic of the 1064-nm laser), likely to detect the coral fluorescence

2 as well as intermediate states (Sasano et al. 2012).

\subsection{Moorea coral reef states' spatial patterns}

The coral reef state classification, spatially-classified at VHR, is a strong asset to outline hotspots of health coral reefs, thus of associated biodiversity and ecosystem services. The centimetre and decimetre scales targeted in this study greatly enhance the spatial resolution of coral reefs' diagnoses and prognoses, surpassing other recent studies using object-based image analysis, which bottom at $2 \mathrm{~m}$ or $10 \mathrm{~m}$ (Phinn, Roelfsema, Mumby 2012; Roelfsema et al. 2013). LiDAR-based spatially-explicit classification, provided with decimetre sounding density over $100 \mathrm{~km}^{2}$, offers an unpublished map of Moorea coral reefs' health. Two main spatial patterns emerged from the spatially-explicit classification: westward polarization of healthy fringing reefs and northward polarization of healthy barrier reefs.

Wide healthy fringing reefs along west shorelines strongly contrast with thin ones along eastern coast. This outstanding geographic difference is very susceptible to be the consequence of the dominant easterly winds (i.e., Southeast trade winds), which entail significantly greater amounts of rain then carried sediment, which, in turn, deposit onto and stress coral colonies (Fabricius 2005), impeding development of eastern fringing coral reefs.

More extended barrier reefs are obvious in the northern compared to southern lagoon. This patterning might be explained by the two dominant swell systems originating from South: 40\% SE and 25\% SSW (Etienne 2012). Swell average height tends to be higher than $4 \mathrm{~m}$ during Austral winter, what creates, at the reef, significant wave height greater than $8 \mathrm{~m}$ (e.g. Teahupoo spot in Southern Tahiti Iti, Etienne 2012). The exposure to this high to very high energy flow hinders the efficient settlement of coral larvae and breaks the coral assemblage structure (Madin and Connolly 2006). This interpretation is corroborated by the third dominant swell system (22\% NE, Etienne 2012), which constrains NE lagoon to exhibit slightly less extended barrier reefs compared to NW.

\section{Conclusion}

This original research has demonstrated that airborne bathymetric LiDAR data are able to reliably map five ecological states in coral reef systems at VHR over shallow, clear waters. Reef state information can be gleaned from an airborne drone equipped with a multispectral imaging sensor. Novel findings can be summarized as follows:

(1) Coral reef state at the colony-scale (pixel size $=0.03 \mathrm{~m}$ ) can be sourced from a BGR camera mounted on an airborne low-altitude drone;

(2) LiDAR surface and intensity are powerful predictors of coral reef ecological state at the colony-scale (pixel size $=0.03 \mathrm{~m}$ );

(3) ANN is an efficient classification approach to predict ecological state based only LiDAR surface and intensity $(\mathrm{OA}=0.75)$;

(4) LiDAR surface and intensity are powerful predictors of ecological state at the landscape scale (pixel size $=0.5 \mathrm{~m}$ );

(5) Healthy fringing and barrier coral reefs in Moorea are located on the western and northern parts of the lagoon, respectively.

\section{Acknowledgements}


Authors gratefully thank Service Hydrographique et Océanographique de la Marine for the LiDAR acquisition control, and the IDEA Consortium for sparking this collaborative research. This work was partly supported by French Polynesia government for LiDAR acquisition, the ETH Zurich for purchasing satellite imagery, and the National Science Foundation through the Moorea Coral Reef LTER (OCE-1236905 and 1637396) and Physical Oceanography (OCE143133) programs. Two valuable referees and the editor are deeply acknowledged for the manuscript improvement.

\section{References}

Adjeroud, M., F. Michonneau, P.J. Edmunds, Y. Chancerelle, T.L. De Loma, L. Penin, L. Thibaut, J. Vidal-Dupiol, B. Salvat, and R. Galzin. 2009. "Recurrent disturbances, recovery trajectories, and resilience of coral assemblages on a South Central Pacific reef." Coral Reefs 28(3) 775-780.

Bellwood, D.R., T.P. Hughes, C. Folke, and M. Nystrom. 2004. "Confronting the coral reef crisis." Nature 429(6994): 827.

Casella, E., A. Collin, D. Harris, S. Ferse, S. Bejarano, V. Parravicini, V., J.L. Hench, and A. Rovere. 2017. "Mapping coral reefs using consumer-grade drones and structure from motion photogrammetry techniques". Coral Reefs 36(1): 269-275.

Collin, A., and S. Planes. 2012. "Enhancing coral health detection using spectral diversity indices from worldview-2 imagery and machine learners." Remote Sensing 4(10): 32443264.

Collin, A., B. Long, B., and P. Archambault. 2011. "Benthic classifications using bathymetric LIDAR waveforms and integration of local spatial statistics and textural features." Journal of Coastal Research 62: 86-98.

Collin, A., J. Laporte, B. Koetz, F.R. Martin-Lauzer, and Y.L. Desnos. 2016. "Mapping bathymetry, habitat, and potential bleaching of coral reefs using Sentinel-2." In Proceedings of the $13^{\text {th }}$ International Coral Reef Symposium, Honolulu, 373-387.

Collin, A., J.L. Hench, and S. Planes. 2012. "A novel spaceborne proxy for mapping coral cover." In Proceedings of the $12^{\text {th }}$ International Coral Reef Symposium, Cairns, 1-5.

Collin, A., K. Nadaoka, and L. Bernardo. 2015. "Mapping the Socio-Economic and Ecological Resilience of Japanese Coral Reefscapes across a Decade." ISPRS International Journal of Geo-Information, 4(2), 900-927.

Collin, A., N. Lambert, and S. Etienne. 2018. "Satellite-based salt marsh elevation, vegetation height, and species composition mapping using the superspectral WorldView-3 imagery." International Journal of Remote Sensing : 1-19. doi: 10.1080/01431161.2018.1466084

Collin, A., P. Archambault, and B. Long. 2008. "Mapping the shallow water seabed habitat with the SHOALS." IEEE Transactions on Geoscience and Remote Sensing 46(10): 2947-2955.

Collin, A., P. Archambault, and B. Long. 2011. "Predicting species diversity of benthic communities within turbid nearshore using full-waveform bathymetric LiDAR and machine learners." PloS one 6(6): e21265.

Collin, A., P. Archambault, and S. Planes. 2014. "Revealing the regime of shallow coral reefs at patch scale by continuous spatial modeling." Frontiers in Marine Science 1: 65.

Collin, A., S. Etienne, and E. Feunteun, E. 2017. "VHR coastal bathymetry using WorldView-3: colour versus learner." Remote Sensing Letters 8(11): 1072-1081.

Congalton, R.G., and K. Green. 2009. Assessing the accuracy of remotely sensed data: principles and practices. CRC/Taylor Francis press.

Costa, B.M., T.A. Battista, and S.J. Pittman. 2009. "Comparative evaluation of airborne LiDAR and ship-based multibeam SoNAR bathymetry and intensity for mapping coral reef ecosystems." Remote Sensing of Environment 113(5): 1082-1100.

Cressey, D. 2015. "Tropical paradise inspires virtual ecology lab.” Nature 517:255-256.

Davies, N., D. Field, D. Gavaghan, S.J. Holbrook, S. Planes, M. Troyer, M. Bonsall, J. Claudet, G. Roderick, R.J. Schmitt, L.A. Zettler, V. Berteaux, H.C. Bossin, C. Cabasse, A. Collin, J. Deck, T. Dell, J. Dunne, R. Gates, M. Harfoot, J.L. Hench, M. Hopuare, P. Kirch, G. Kotoulas, A. Kosenkov, A. Kusenko, J.J. Leichter, H. Lenihan, A. Magoulas, N. Martinez, 
C. Meyer, B. Stoll, B. Swalla, D.M. Tartakovsky, H.T. Murphy, S. Turyshev, F. Valdvinos, R. Williams, S. Wood, Consortium I. 2016. "Simulating social-ecological systems: the Island Digital Ecosystem Avatars (IDEA) consortium." Gigascience 5:14.

Fabricius, K.E. 2005. "Effects of terrestrial runoff on the ecology of corals and coral reefs: review and synthesis." Marine pollution bulletin 50(2): 125-146.

Goodman, J.A., J.P. Samuel, and R.P. Stuart. 2013. Coral reef remote sensing. A guide for mapping, monitoring and management. Springer: Netherlands.

Hedley, J.D., C.M. Roelfsema, I. Chollett, A.R. Harborne, S.F. Heron, S. Weeks, W.J. Skirving, A.E. Strong, C.M. Eakin, T.R.L. Christensen, V. Ticzon, S. Bejarano, and P.J. Mumby. 2016. "Remote Sensing of Coral Reefs for Monitoring and Management: A Review." Remote Sens. 8: 118.

Heermann, P.D., and N. Khazenie. 1992. "Classification of multispectral remote sensing data using a back-propagation neural network." IEEE Transactions on Geoscience and Remote Sensing 30(1): 81-88.

Knudby, A., S. Jupiter, C. Roelfsema, M. Lyons, and S. Phinn. 2013. "Mapping coral reef resilience indicators using field and remotely sensed data." Remote Sensing 5(3): 1311-1334.

Leiper, I.A., S.R. Phinn, C.M. Roelfsema, K.E. Joyce, and A.G. Dekker. 2014. "Mapping coral reef benthos, substrates, and bathymetry, using compact airborne spectrographic imager (CASI) data." Remote Sensing 6(7): 6423-6445.

Leiper, I.A., U.E. Siebeck, N.J. Marshall, and S.R. Phinn. 2009. "Coral health monitoring: linking coral colour and remote sensing techniques." Canadian Journal of Remote Sensing 35(3): 276-286.

Leon, J.X., C.M. Roelfsema, M.I. Saunders, and S.R. Phinn. 2015. "Measuring coral reef terrain roughness using 'Structure-from-Motion' close-range photogrammetry." Geomorphology 242: 21-28.

Madin, J.S., and S.R. Connolly. 2006. "Ecological consequences of major hydrodynamic disturbances on coral reefs." Nature 444(7118): 477-480.

Pastol, Y., L. Chamberlain, and M. Sinclair. 2016. "Airborne Bathymetric LiDAR and Coastal Zone Management in French Polynesia." In Proc. of International Federation of Surveyors (FIG) Working Week, Christchurch, May 2-6.

Phinn, S.R., C.M. Roelfsema, and P.J. Mumby. 2012. "Multi-scale, object-based image analysis for mapping geomorphic and ecological zones on coral reefs." International Journal of Remote Sensing 33(12) : 3768-3797.

Service Hydrographique et Océanographique de la Marine (SHOM). 2016. Lidar Polynésie française 2015 Produit Moorea SAU V. 20160630.

Sasano, M., H. Yamanouchi, A. Matsumoto, N. Kiriya, K. Hitomi, and K. Tamura. 2012. "Development of boat-based fluorescence imaging lidar for coral monitoring." In Proc. of 12th Internaitonal Coral Reef Symposium, Cairns, 5A-7.

Roelfsema, C., S. Phinn, S. Jupiter, J. Comley, and S. Albert. 2013. "Mapping coral reefs at reef to reef-system scales, $10 \mathrm{~s}-1000 \mathrm{~s} \mathrm{~km} 2$, using object-based image analysis." International journal of remote sensing 34(18): 6367-6388.

Rowlands, G., S. Purkis, B. Riegl, L. Metsamaa, A. Bruckner, and P. Renaud. 2012. "Satellite imaging coral reef resilience at regional scale. A case-study from Saudi Arabia." Marine Pollution Bulletin 64(6): 1222-1237.

Wedding, L.M., A.M. Friedlander, M. McGranaghan, R.S. Yost, and M.E. Monaco. 2008. "Using bathymetric lidar to define nearshore benthic habitat complexity: Implications for management of reef fish assemblages in Hawaii." Remote Sensing of Environment 112(11): 4159-4165. 
(a)

(b)

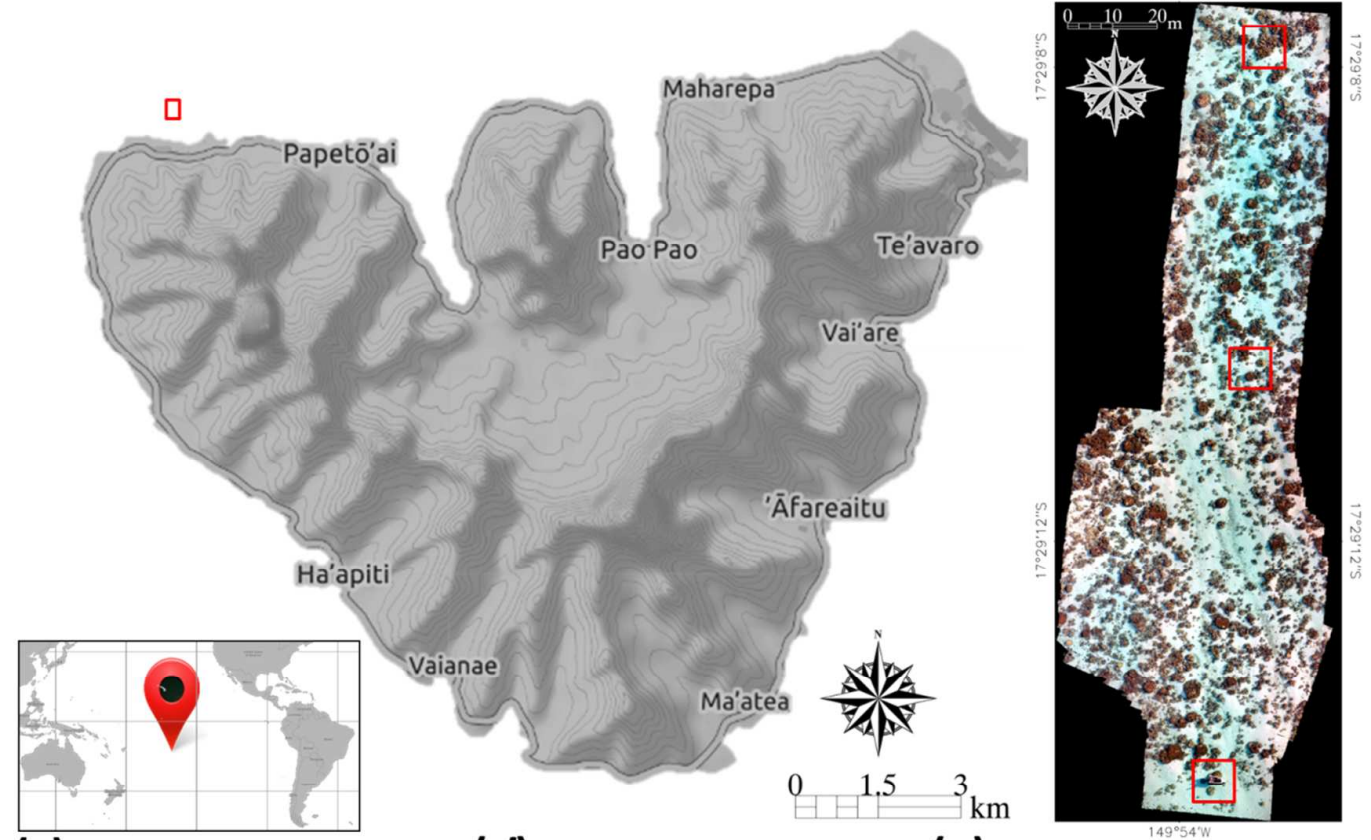

\section{(c)}

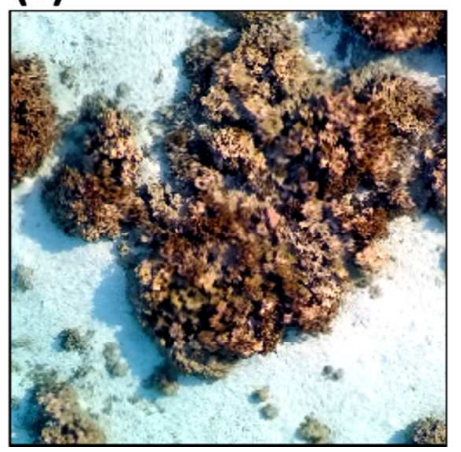

(d)

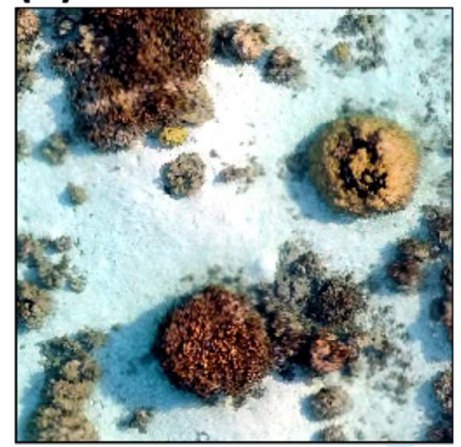

(e)

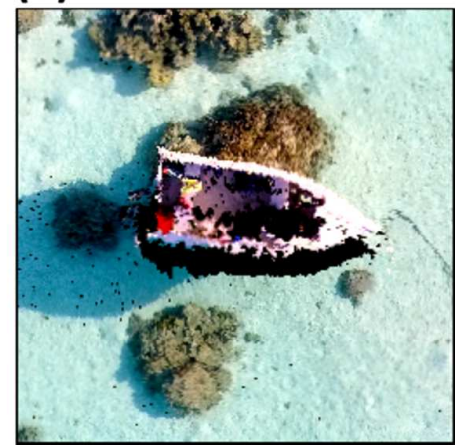

Figure 1. (a) Moorea Island (French Polynesia) was surveyed by bathymetric LiDAR at island scale (10-26 June 2015) and over a small study area by airborne drone (17 August 2015; red rectangle). (b) Natural-coloured (blue-green-red) drone survey provides spectral information at $0.03 \mathrm{~m}$ pixel size $(2133 \times 6095$ pixels $)$, enabling resolution of coral reef $(c)$ assembled colonies, 6 (d) single colonies on sand/pavement, or $(e)$ anthropogenic features. 
(a)

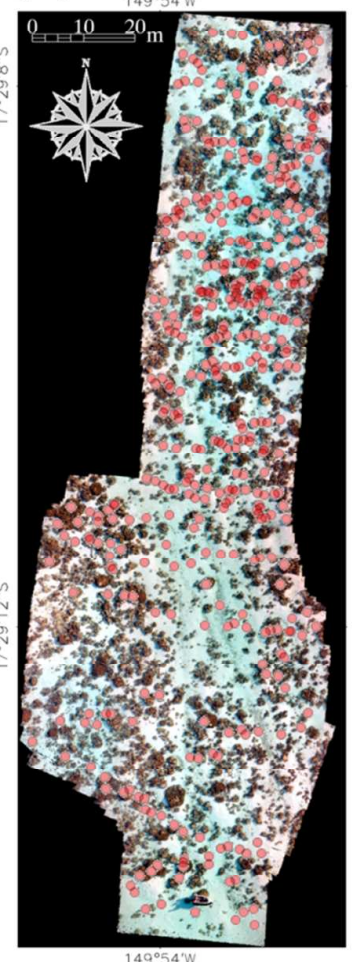

(b)

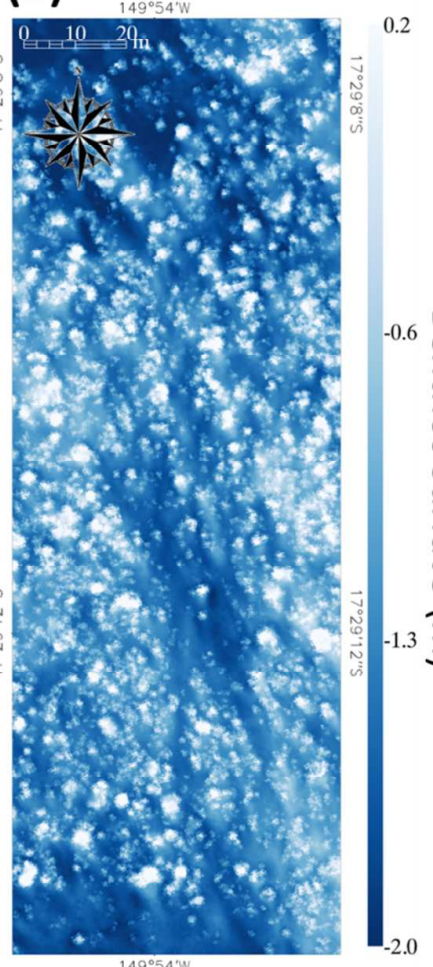

(c)

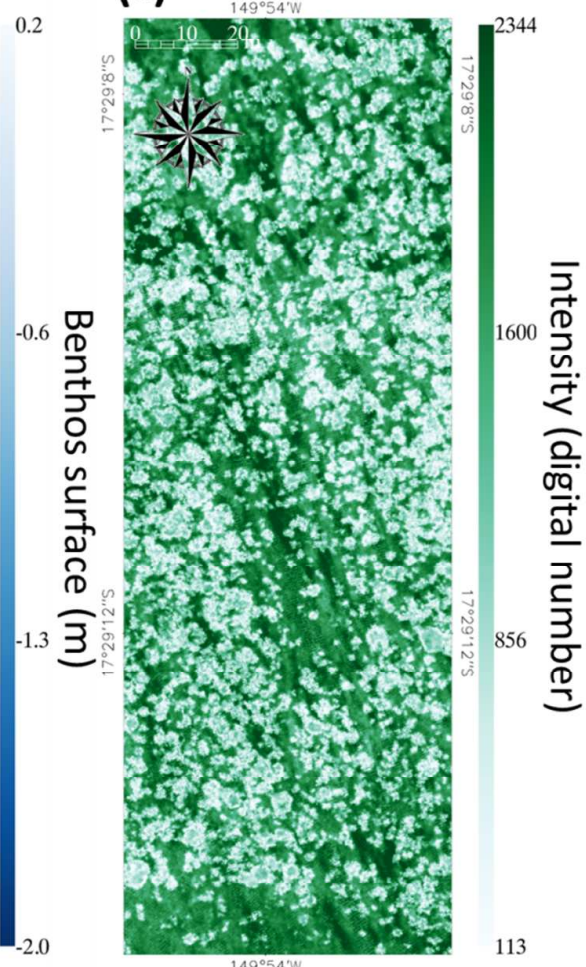

Figure 2. Maps of the $(a)$ natural-coloured imagery with 410 air-truth sampling sites (red transparent disks), (b) bathymetric LiDAR surface soundings, and (c) bathymetric LiDAR intensity (532 nm wavelength) soundings. $(a)$ is at $0.03 \mathrm{~m}$, whereas $(b)$ and $(c)$ are at $0.5 \mathrm{~m}$ pixel size.

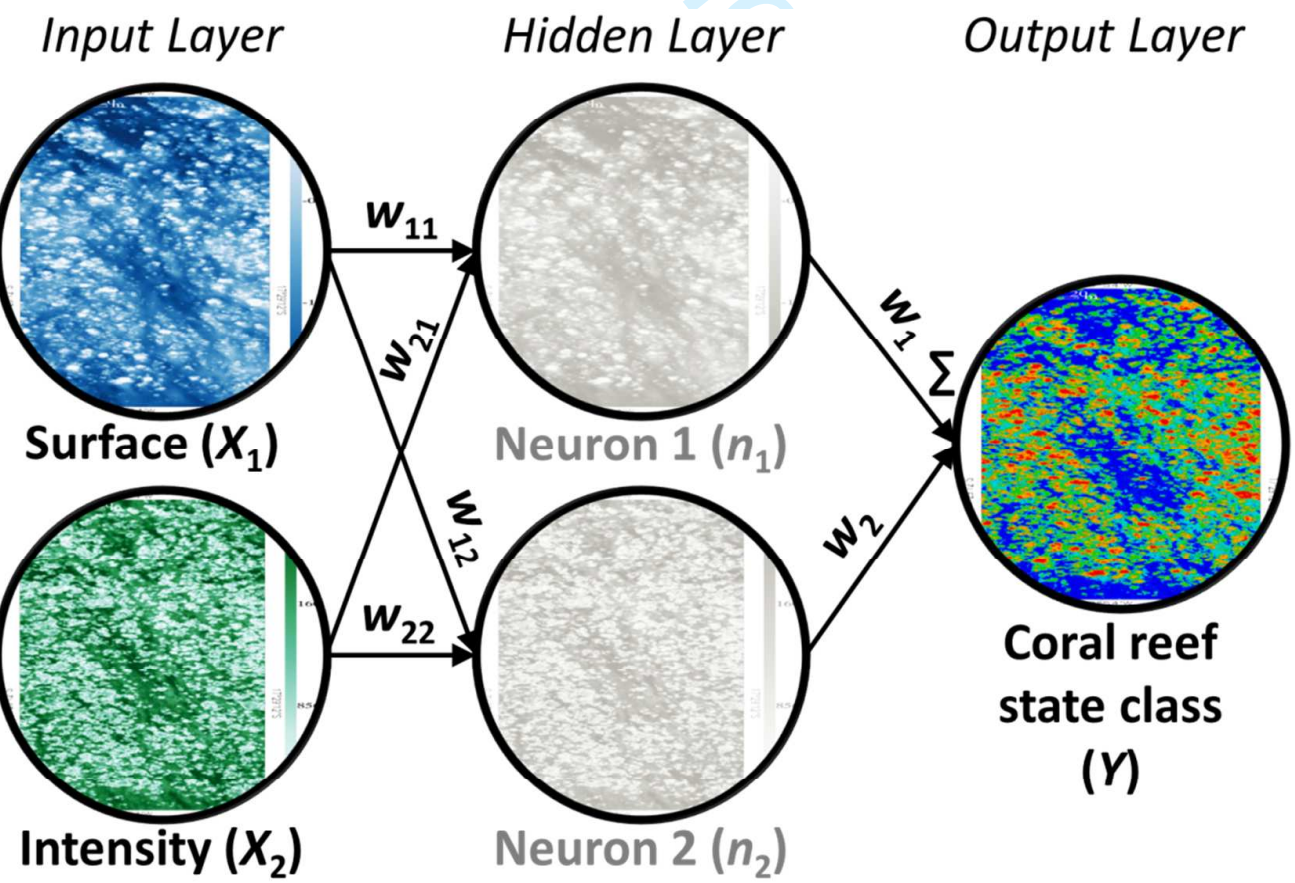

Figure 3. Conceptual flowchart explaining how the combination of LiDAR surface and 9 intensity can predict the ecological state class through an intermediate hidden layer provided 10 with two neurons. 


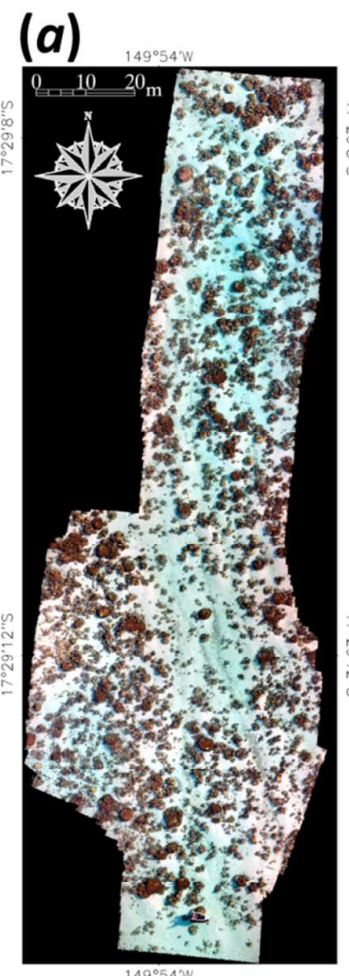

(b)

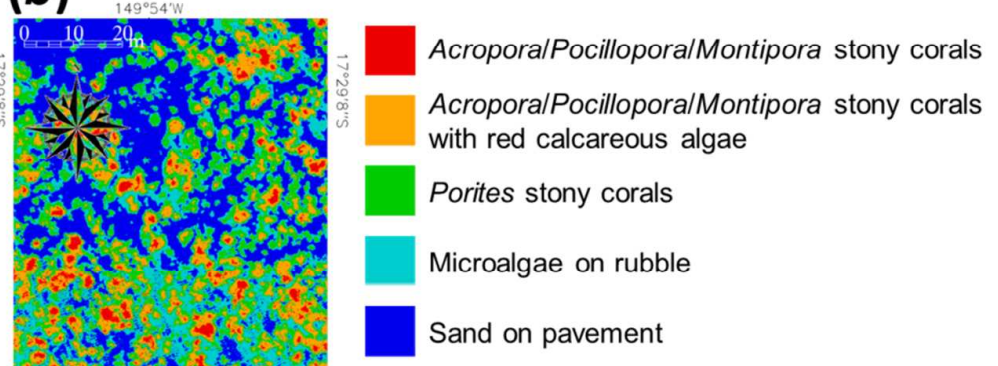



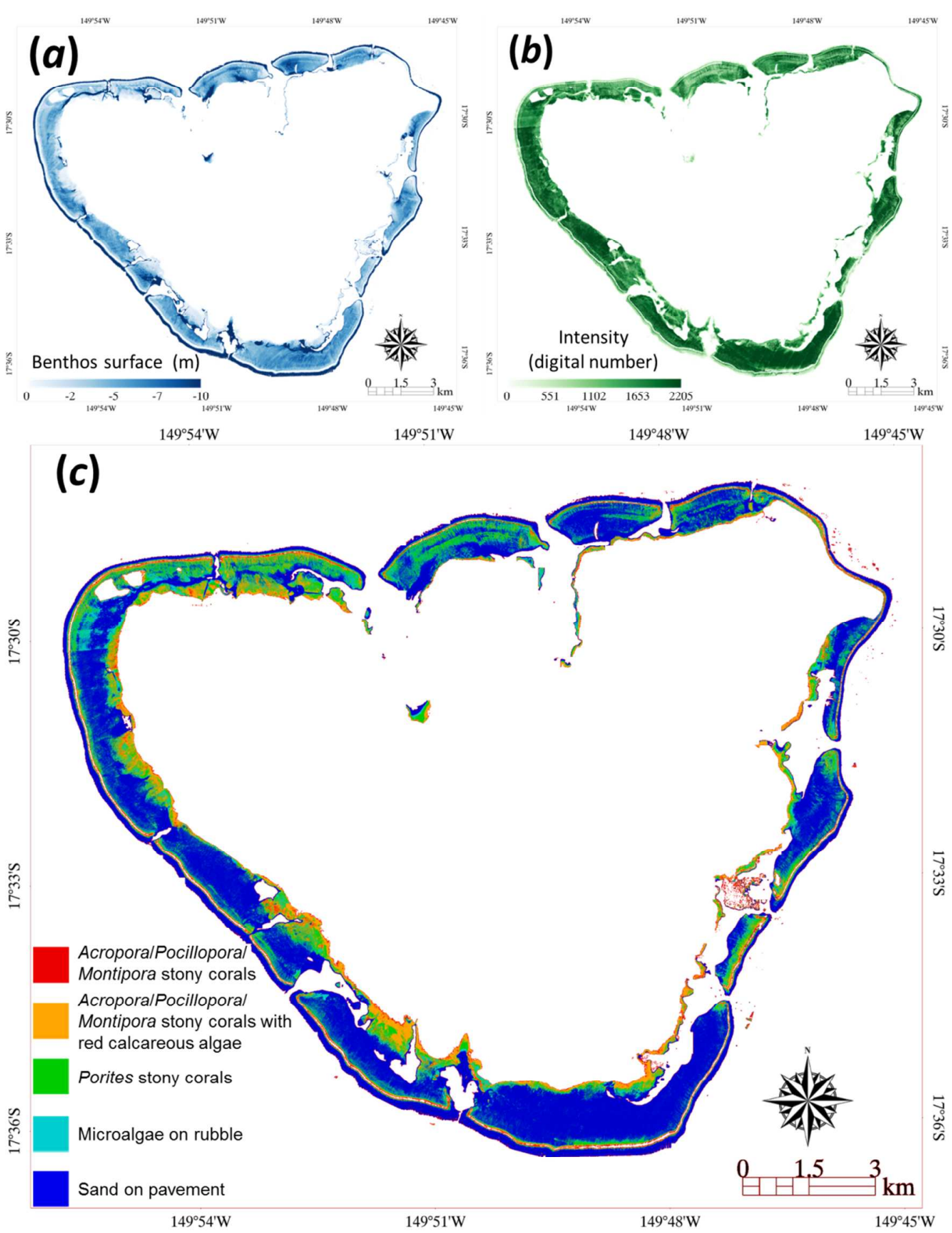

Figure 5. Digital (a) surface, (b) intensity (532 nm wavelength), and (c) coral reef state classification derived from bathymetric LiDAR soundings $(40364 \times 34588$ pixels at $0.5 \mathrm{~m}$ pixel size). 
2

3

4

1 Table 1. Ecological description of the five coral reefscape states identified on airborne drone 2 blue-green-red imagery ( $0.03 \mathrm{~m}$ spatial resolution) enabling a coral reef state classification to be 3 created and colour-coded.

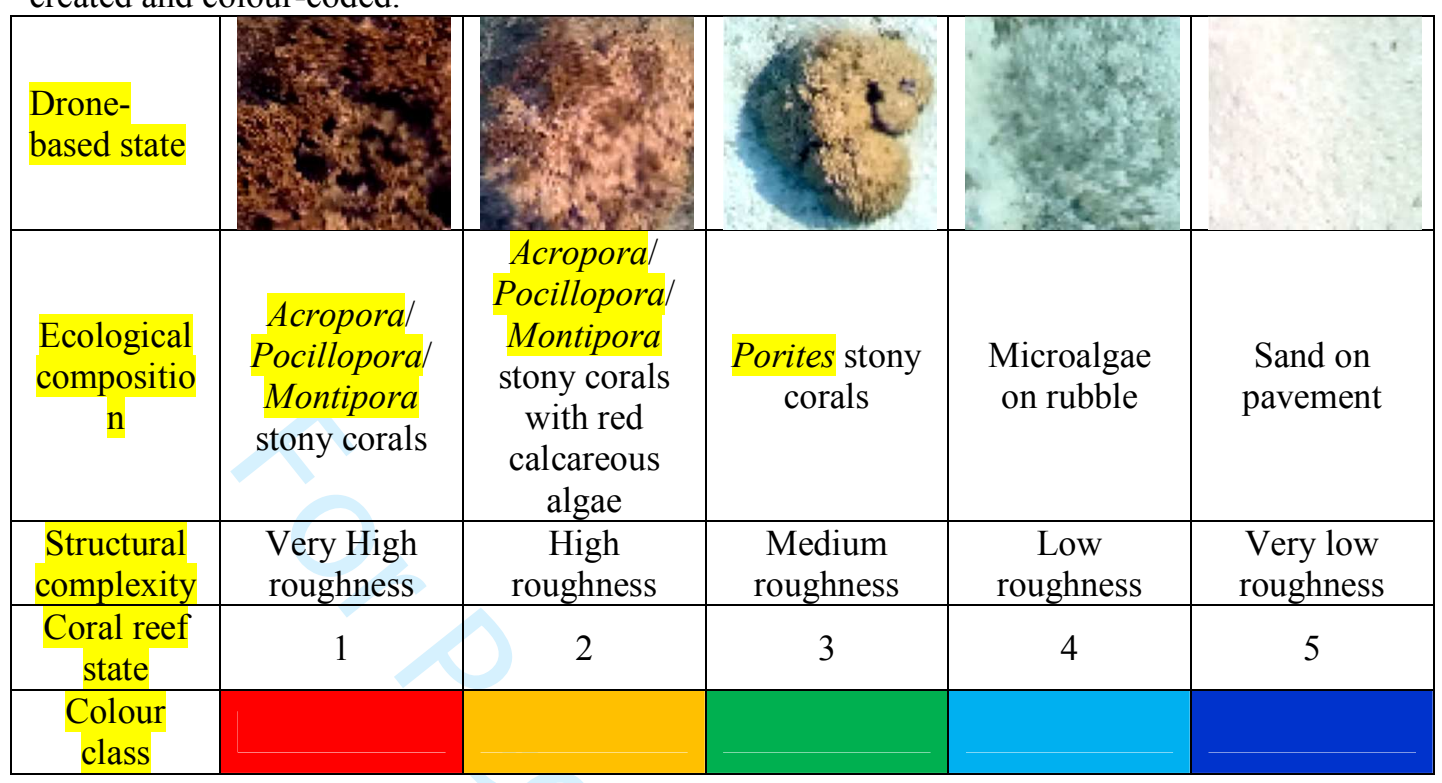

4

Table 2. Confusion matrix synthesizing the quality of the artificial neural network classification applied to the independent 135 validation pixels (27 pixels per coral reef state).

\begin{tabular}{|c|c|c|c|c|c|c|c|c|}
\hline & & \multicolumn{5}{|c|}{ Reference class } & & \\
\hline & STATE & 1 & 2 & 3 & 4 & 5 & Total & UA \\
\hline \multirow{7}{*}{$\begin{array}{l}\text { Classified } \\
\text { class }\end{array}$} & 1 & 21 & 2 & 2 & 0 & 0 & 25 & 0.84 \\
\hline & 2 & 4 & 17 & 3 & 1 & 0 & 25 & 0.68 \\
\hline & 3 & 1 & 3 & 20 & 2 & 1 & 27 & 0.74 \\
\hline & 4 & 0 & 1 & 1 & 19 & 7 & 28 & 0.68 \\
\hline & 5 & 0 & 1 & 2 & 3 & 24 & 30 & 0.80 \\
\hline & Total & 26 & 24 & 28 & 25 & 32 & 135 & \\
\hline & PA & 0.80 & 0.71 & 0.71 & 0.76 & 0.75 & & \\
\hline
\end{tabular}

